\title{
Incidence and Clinical Outcome of Acute Kidney Injury in Patients with Sepsis Admitted in Multi-Disciplinary Unit in a Tertiary Care Center
}

\author{
Hussain Khan Tharappel Jalal ${ }^{1}$, Teju Parankimamoottil Thomas², Sreedas Gopalakrishnan³ ${ }^{3}$ Hamdan Mohammed $^{4}$ \\ ${ }^{1}$ Department of Medicine, Travancore Medical College, Kollam, Kerala, India. ${ }^{2}$ Department of Critical Care Medicine, \\ Travancore Medical College, Kollam, Kerala, India. ${ }^{3}$ Department of Nephrology, Travancore Medical College, Kollam, \\ Kerala, India. ${ }^{4}$ Department of Medicine, Travancore Medical College, Kollam, Kerala, India.
}

\section{ABSTRACT}

\section{BACKGROUND}

A rising trend has been reported in Acute Kidney Injury (AKI) in both developed and developing countries and there is an independent association with increased morbidity and mortality with sepsis being the most common predisposing factor. Sepsis and cardiovascular causes resulted in a high incidence of AKI, and older age was also an important risk factor. Our study aims to determine the incidence, outcome and comorbidities associated with AKI in sepsis patients. Sepsis is a serious medical condition characterized by a whole-body inflammatory state (systemic inflammatory-response syndrome) and the presence of a known or suspected infection that has severe consequences, including multiple organ failure.

\section{METHODS}

We did a retrospective observational study in 497 sepsis patients admitted in MDICU. Acute kidney injury in these patients was identified and studied using RIFLE criteria between June 2016 and May 2017.

\section{RESULTS}

A total of 497 patients were studied. Mean age was 60 yrs. $59.8 \%$ were males and 40.2\% were females. 279 have acute kidney injury; so, incidence of AKI in our study is $56.1 \%$. Significant comorbidities associated with AKI are diabetes mellitus $61.6 \%$ $(\mathrm{p}=0.001)$, hypertension 76.7\% ( $\mathrm{p}=0.001)$, CKD 43.3\% ( $\mathrm{p}=0.001)$, CAD $28.3 \%$ ( 0.020). Out of 279 AKI cases, 167 (59.9\%) were under RISK, 94 (33.7\%) were under kidney injury, 18 (6.5\%) under renal failure. 246 (88.1\%) received conservative management and $33(11.9 \%)$ received renal replacement therapy. Out of 33 patients receiving RRT, 18 patients (54.5\%) expired during the study period ( $p$ value 0.011$)$. 14 patients $(50 \%)$ of those who received early RRT died and 14 patients (50\%) survived, whereas in late RRT $4(80 \%)$ died and 1 patient $(20 \%)$ survived. There is no statistically significant $(p=0.25)$ association between mortality and early or late initiation of RRT.

\section{CONCLUSIONS}

As the incidence of AKI is $56.1 \%$ and there is significant association between sepsis patients with AKI and comorbidity, high RIFLE score and mortality, RRT and mortality. So Specific goals for reducing incidence and mortality of acute kidney injury has to be formulated and uniform guidelines regarding initiating RRT should be formed.

\section{KEY WORDS}

Sepsis, Acute Kidney Injury, Rifle, AKI Outcome
Corresponding Author:

Teju Parankimamoottil Thomas,

Kripa, Parankimamoottil,

Kizhakketheruvu P. O.,

Kottarakkara, Kollam-691541,

Kerala, India.

E-mail:tejupt@gmail.com

DOI: $10.14260 / j e m d s / 2019 / 846$

Financial or Other Competing Interests: None.

How to Cite This Article: Jalal HKT, Thomas TP, Gopalakrishnan S, et al. Incidence and clinical outcome of acute kidney injury in patients with sepsis admitted in multi-disciplinary unit in a tertiary care center. J. Evolution Med. Dent. Sci. 2019;8(52):3904-3908, DOI: $10.14260 / j e m d s / 2019 / 846$

Submission 14-10-2019,

Peer Review 13-12-2019,

Acceptance 20-12-2019,

Published 30-12-2019.

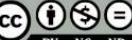




\section{BACKGROUND}

A rising trend has been reported in Acute Kidney Injury (AKI) in both developed and developing countries and there is an independent association with increased morbidity and mortality in children as well as in adults and subsequent CKD.[1] Incidence of AKI in critically ill patients varied between 15 to $50 \%$ in multiple epidemiological investigations. ${ }^{[2]} 5.7 \%$ of emergency hospital admission is complicated by AKI and it rose $30 \%$ in the setting of diarrhoeal illness, infectious diseases like malaria and leptospirosis and natural disasters like earth quakes.[3] In acutely ill sepsis is the most common predisposing factor for AKI.[4] The yearly incidence of AKI in US is estimated to be 500 per 100000 population higher than yearly incidence of stroke.[5] The clinical diagnosis of sepsis requires finding a focus of infection as well as at least two signs of systemic inflammatory-response syndrome that comprise abnormal body temperature (higher than $38^{\circ} \mathrm{C}$ or less than $36^{\circ} \mathrm{C}$ ), heart rate $>90$ beats $/ \mathrm{min}$, respiration $>20$ breaths $/ \mathrm{min}$ or arterial partial pressure of $\mathrm{CO} 2<32 \mathrm{mmHg}$, and deranged white blood cell counts (greater than $12 \times 103 / \mathrm{mm}^{3}$, less than $4 \times$ $103 / \mathrm{mm}^{3}$, or greater than $10 \%$ bands). $\left.{ }^{4}\right]$

Only in 2004 AKI has got a uniform definition when the acute dialysis quality initiative (ADQI) proposed the Risk, Injury, Failure, Loss and End stage Kidney disease (RIFLE) criteria.[6] Development of the RIFLE criteria allowed clinicians worldwide to identify and track patients with AKI in a uniform manner. The basic component of RIFLE criteria are variations in serum creatinine and urine output. Increase in severity level increases the specificity of the classification system, with reduction in sensitivity.[7] In 2007 RIFLE criteria was modified by Acute Kidney Injury Network (AKIN) and in 2012 Kidney Disease Improving Global Outcomes (KDIGO) came out with new criteria for AKI. KDIGO reported that there is 17 to $30 \%$ incidence of AKI in hospitalized patients. ${ }^{[8-}$ 10] $68 \%$ of a large cohort of 5443 patients with septic shock developed AKI within 6 hours of presentation and mechanism of development of AKI was individualistic.[11,12] It is yet to understand the potential difference between outcome association and grading of AKI severity in severe sepsis or septic shock.[13]

Individuals with comorbidities have increased risk of developing AKI.[14] Presence of more than one comorbidity result in high severity of result score in AKI.[15] It is shown that comorbidities such as hypertension, diabetes mellitus, heart disease, chronic renal disease predispose a patient to progress with AKI.[16] Increased long term mortality was associated with pre-existing comorbidity than severity of AKI episode.[17] Thus comorbidities play an important role in development, progression of AKI and long term morbidity and mortality.

Among patient admitted to the ICU, mortality rate may exceed $50 \%$. Even patients surviving an episode of severe AKI, requiring dialysis are at increased risk of later development of ESRD. [5] It was shown that as the severity of AKI increased so did the mortality. Mortality was $5.5 \%$ in patients without $\mathrm{AKI}$ and it increases to $8.8 \%$ in risk group and $26.3 \%$ in failure group in RIFLE criteria.[18]In 1996 2008, 4.4 community acquired AKI in 1000 admission with a mortality of $10.98 \%$ was reported in India.[19] Prolonged intensive care stay, repeated investigations, RRT, cardiac complications and re-admission have increased the health care cost.[20,21] National Confidential Enquiry into Patient Outcomes and Death (NCEPOD) Singapore 2009 reported that among AKI death 50\% received suboptimal care and $14 \%$ was avoidable AKI.[22] 0 by 25 is an initiative by International Society of Nephrology for eliminating preventable death from AKI by 2025 through improving timely diagnosis and treatment.[23]

There is less data regarding the incidence and outcome of AKI in critically ill patients from South India, especially in Kerala. In view of this, we have conducted a retrospective study of Patients who have been admitted to the medical ICU in a tertiary care centre in South India.

We wanted to determine the incidence, outcome and comorbidities of AKI in sepsis patient.

\section{METHODS}

After obtaining the ethical committee clearance fro the study, patients were included in the study as per inclusion and exclusion criteria, using purposive sampling method till required sample size was achieved. A diagnosis of sepsis was made based on the diagnosis documented at the point of admission by the treating clinician. Patients were assigned to rifle classes at the time of admission.

This is a retrospective observational study in 497 patients with sepsis $>18$ years admitted in MDICU at Travancore Medical College, Kollam between June -2016 and May-2017. The sample size was taken based on the convenience of the study. We excluded patients with ESRD and those who were lost follow up. Patients filling the inclusion criteria were taken into the study using purposive sampling method till required sample size was achieved. Diagnosis of sepsis was made based on the diagnosis documented at the point of admission by the treating clinician. Patients were assigned to RIFLE class at the time of admission.

\begin{tabular}{|c|c|c|c|}
\hline & GFR criteria* & Urine output criteria* & \multirow{5}{*}{ High sensitivity } \\
\hline Risk & $\begin{array}{l}\text { Increased SCreat } \times 1.5 \\
\text { or GFR decrease }>25 \%\end{array}$ & UO $<0.5 \mathrm{~mL} / \mathrm{kg} / \mathrm{h} \times 6 \mathrm{~h}$ & \\
\hline & & & \\
\hline Injury & $\begin{array}{l}\text { Increased SCreat } \times 2 \\
\text { or GFR decrease }>50 \%\end{array}$ & $\mathrm{U} O<0.5 \mathrm{~mL} / \mathrm{kg} / \mathrm{h} \times 12 \mathrm{~h}$ & \\
\hline Failure & $\begin{array}{l}\text { Increased SCreat } \times 3 \\
\text { GFR decrease } 75 \% \\
\text { or SCreat } \geq 4 \mathrm{mg} / \mathrm{dL} \\
\text { Acute rise } \geq 0.5 \mathrm{mg} / \mathrm{dL}\end{array}$ & $\begin{array}{l}\text { UO }<0.3 \mathrm{~mL} / \mathrm{kg} / \mathrm{h} \times 24 \mathrm{~h} \\
\text { or anuria } \times 12 \mathrm{~h}\end{array}$ & \\
\hline Loss & \multicolumn{2}{|c|}{$\begin{array}{l}\text { Persistent ARF }{ }^{* *}=\text { complete loss } \\
\text { of kidney function }>4 \text { weeks }\end{array}$} & \multirow{2}{*}{ High specificity } \\
\hline ESKD & \multicolumn{2}{|c|}{ End-stage kidney disease (> 3 months) } & \\
\hline \multicolumn{4}{|c|}{ AKI Based on the RIFLE Criteria Reference ${ }^{(18)}$} \\
\hline Source: I & & & \\
\hline
\end{tabular}

Required data collected from the clinical records of patient fitting the criteria. Those patients who received RRT from risk and injury group are defined as early RRT and from failure group as late RRT. Indication for initiating dialysis 
include anuria, fluid overload, uraemia, hyperkalaemia, refractory acidosis.

\section{Statistical Analysis}

The data collected was entered in Microsoft Excel and analyzed using SPSS V.16. Descriptive analysis was done by calculating frequencies and proportions. Chi square test was used to calculate statistical significance.

\section{RESULTS}

\begin{tabular}{|c|c|c|}
\hline Age Group & Frequency (n=497) & Percentage (\%) \\
\hline $18-40$ & 85 & 17.1 \\
\hline $40-60$ & 170 & 34.2 \\
\hline$>60$ & 242 & 48.7 \\
\hline Gender & & 59.8 \\
\hline Male & 297 & 40.2 \\
\hline Female & 200 & 56.1 \\
\hline AKI & 279 & 43.9 \\
\hline Present & 218 & \\
\hline Absent Table 1. Demography Distribution \\
\hline \multicolumn{2}{|c|}{} \\
\hline
\end{tabular}

\begin{tabular}{|c|c|c|}
\hline Age Group & AKI \\
\hline & Present & Absent \\
\hline $18-40$ & $25(9.0 \%)$ & $60(27.5 \%)$ \\
\hline $40-60$ & $111(39.8 \%)$ & $59(27.1 \%)$ \\
\hline$>60$ & $143(51.3 \%)$ & $99(45.4 \%)$ \\
\hline \multicolumn{3}{|c|}{ Table 1a. AKI Distribution } \\
\hline
\end{tabular}

\begin{tabular}{|c|c|c|c|c|}
\hline \multirow{2}{*}{ Comorbidity } & \multicolumn{2}{|c|}{ AKI } & \multirow{2}{*}{$\begin{array}{c}\text { Chi Square } \\
\text { Value }\end{array}$} & \multirow{2}{*}{ p Value } \\
\hline & Yes & No & & \\
\hline Yes & $248(65.4 \%)$ & $131(34.6 \%)$ & \multirow{2}{*}{56.052} & \multirow{2}{*}{$0.001^{*}$} \\
\hline No & $31(26.3 \%)$ & $87(73.7 \%)$ & & \\
\hline \multicolumn{5}{|l|}{ Diabetes Mellitus } \\
\hline Yes & $172(67.5 \%)$ & $83(32.5 \%)$ & \multirow{2}{*}{27.226} & \multirow{2}{*}{$0.001^{*}$} \\
\hline No & $107(44.2 \%)$ & $135(55.8 \%)$ & & \\
\hline \multicolumn{5}{|l|}{ Hypertension } \\
\hline Yes & $214(69.5 \%)$ & $94(30.5 \%)$ & \multirow{2}{*}{58.567} & \multirow{2}{*}{$0.001^{*}$} \\
\hline No & $65(34.4 \%)$ & $124(65.6 \%)$ & & \\
\hline \multicolumn{5}{|l|}{ CKD } \\
\hline Yes & $121(91.7 \%)$ & $11(8.3 \%)$ & \multirow{2}{*}{92.146} & \multirow{2}{*}{$0.001^{*}$} \\
\hline No & $158(43.3 \%)$ & $207(56.7 \%)$ & & \\
\hline \multicolumn{5}{|l|}{ CAD } \\
\hline Yes & $79(65.3 \%)$ & $42(34.7 \%)$ & \multirow{2}{*}{5.441} & \multirow{2}{*}{$0.020^{*}$} \\
\hline No & $200(53.2 \%)$ & $176(46.8 \%)$ & & \\
\hline \multicolumn{5}{|l|}{ CVA } \\
\hline Yes & $41(56.2 \%)$ & $32(43.8 \%)$ & \multirow{2}{*}{0.000} & \multirow{2}{*}{0.996} \\
\hline No & $238(56.1 \%)$ & $186(43.9 \%)$ & & \\
\hline \multicolumn{5}{|c|}{ Table 2. Comorbidity } \\
\hline
\end{tabular}

\begin{tabular}{|c|c|c|}
\hline \multicolumn{3}{|c|}{ RIFLE Score (n=279) Frequency (\%) } \\
\hline Risk & Injury & Failure \\
\hline $167(59.9 \%)$ & $94(33.7 \%)$ & $18(6.5 \%)$ \\
\hline \multicolumn{3}{|c|}{ Table 3. Rifle Score } \\
\hline
\end{tabular}

\begin{tabular}{|c|c|c|c|}
\hline \multirow{2}{*}{$\begin{array}{c}\text { Mode of } \\
\text { Treatment }\end{array}$} & RIFLE Score & & \\
\cline { 2 - 4 } & Risk & Injury & Failure \\
\hline RRT & $19(57.6 \%)$ & $9(27.3 \%)$ & $5(15.2 \%)$ \\
\hline Conservative & $148(60.2 \%)$ & $85(34.6 \%)$ & $4(22.2 \%)$ \\
\hline \multicolumn{4}{|c|}{ Table $3 a$. Mode of Treatment } \\
\hline
\end{tabular}

\begin{tabular}{|c|c|c|c|c|c|}
\hline Mortality & Risk & Injury & Failure & Chi Square Value & p \\
\hline Yes & $11(61.1 \%)$ & $3(16.7 \%)$ & $4(22.2 \%)$ & 9.078 & $0.011^{*}$ \\
\hline No & $156(59.8 \%)$ & $91(34.9 \%)$ & $14(5.4 \%)$ & & \\
\hline \multicolumn{7}{|c|}{ Table 4. Mortality } \\
\hline
\end{tabular}

\begin{tabular}{|c|c|c|c|c|}
\hline \multirow{2}{*}{ RRT } & \multicolumn{2}{|c|}{ Mortality } & Chi Square & \multirow{2}{*}{ p Value } \\
\cline { 2 - 3 } & Expired & Surviving & \multirow{2}{*}{181.410} & \multirow{2}{*}{$0.001^{*}$} \\
\hline Yes & $18(54.5 \%)$ & $15(45.5 \%)$ & & \\
\hline No & $7(1.5 \%)$ & $457(98.5 \%)$ & & 0.215 \\
\hline RRT & & & 1.540 & \\
\hline Early RRT & $14(50.0 \%)$ & $14(50.0 \%)$ & $1(20.0 \%)$ & \\
\hline Late RRT & $4(80.0 \%)$ & Table 4a. Mortality \\
\hline \multicolumn{5}{|c|}{} \\
\hline *Statistically Significant
\end{tabular}

\section{Clinical Characteristics of Patients}

As shown in Table 1, A total of 497 patients studied, 279 have acute kidney injury so incidence of AKI in our study is $56.1 \%$, AKI was found in all age groups (Maximum age was 98 yrs. and Minimum age 18 yrs.) median age 60 yrs. Out of 497 cases studied 297 (59.8\%) were males and 200 (40.2\%) were females.

As shown in Table 2, Among 497 patients with sepsis, 379 (76.3\%) had comorbidities and 118 (23.7\%) had no comorbidities. Among 379, 255 (51.3\%) had DM, 308 (62.0\%) had hypertension, 132 (26.6\%) had chronic kidney disease, 121 (24.3\%) had Coronary Artery Disease. It was observed that out of 279 patients with AKI, 248 (89.9\%) had comorbidities and 31 (11.1\%) had no comorbidities. 214 (76.7\%) had hypertension, 172 (61.6\%) had type 2 DM, 121 (43.4\%) had chronic kidney disease, 79 (28.3\%) had coronary artery disease, 41 (14.7\%) had cerebrovascular accident. Hypertension was most common co morbidity followed by type 2 DM. It is evident that majority had multiple comorbidities. There is significant association between AKI and co morbidity. Significant comorbidities are diabetes mellitus $67.5 \%(\mathrm{p}=0.001)$, Hypertension $69.5 \%(\mathrm{p}$ value 0.001 ), CKD 91.5\% ( $\mathrm{p}=0.001)$, CAD 65.3\% ( $\mathrm{p}=0.020$ )

As shown in Table 3; Severity of AKI was assessed based on RIFLE criteria. Out of 279 AKI cases; 167(59.9\%) were under RISK, 94 (33.7\%) were under kidney injury, 18(6.5\%) under renal failure. Among 279 AKI patients, 246 (88.1\%) received conservative management and 33 (11.9\%) received renal replacement therapy.

From Table 4; There is significant association between rifle score and mortality ( $\mathrm{p}$ value 0.001 ).Out of 18 patients in failure 4 expired which amounts to $22.2 \%$. It can be concluded that $27.7 \%$ of failure required RRT, $9.57 \%$ of the injury and $11.3 \%$ of risk required RRT. There is significant association between RRT and mortality (p value 0.001). Out of 33 patients who received RRT, 15 (45.5\%) patients survived and $18(54.5 \%)$ expired. 14 patients (50\%) of those who receive early RRT died and 14 patients (50\%)survived whereas in late RRT $4(80 \%)$ died and 1 patient $(20 \%)$ survived. There is no statistical significance $(\mathrm{p}$ value $=0.25)$ association between mortality and early or late initiation of RRT.

\section{DISCUSSION}

\section{Incidence}

AKI is a frequently observed clinical syndrome in intensive care unit with overall incidence of 20\%-50\% associated with the mortality rate over $50 \%$. Incidence of AKI in our study is $56.1 \%$, which is higher than the study done in critically ill patients, where incidence varied between $15 \%$ and $50 \% .{ }^{[2]}$ In other study, the incidence of community acquired AKI reported in India was 4.14/1000 admissions in 1996 2008.[19] This shows that incidence of AKI has increased, so further study regarding factors causing increased AKI incidence is required for proper intervention.

\section{Comorbidities and Acute Kidney Injury}

In our study there is significant association between co morbidity and acute kidney injury. Significant co- morbidities 
include hypertension (62\%), type 2 DM (51.3\%), CKD (26.6\%), CAD (24.3\%). This is in accordance with previous study by of the co-morbidities, hypertension was the commonest $(28,57.1 \%)$, with diabetes and ischaemic heart disease present in 27 (55.1\%) and 17 (34.7\%) respectively.[24] In another study by Tariq Ali, Izhar khan et al, comorbidities associated with AKI CAD (29.5\%), hypertension $(27.2 \%)$, CKD (18.56\%), CVA (17.3\%), diabetes (15\%).[25] Sicker patients were more likely to develop AKI and those with SOFA scores greater than $>9$ were more likely to develop AKI, and, as expected, had higher mortality. Sepsis and cardiovascular causes resulted in a high incidence of AKI, and older age was also an important risk factor.[25]

With regards to comorbidities, $302(74.8 \%)$ had hypertension, 230 (56.9\%) had diabetes mellitus, and 187 $(46.3 \%)$ had ischemic heart disease in a study of outcomes of acute kidney injury.[26] Study by Ravindra L Mehta et al, comorbidities associated with AKI are CAD (37\%), CKD (37\%), DM (29\%).[27] Pre-existing CKD increases the risk of non-recovery from AKI. In a large community-based study from North California the risk for death or ESRD 30 days after hospital discharge was increased by $30 \%$ by an episode of AKI. ${ }^{[28]}$ So, AKI is multi factorial with several different insults affecting the kidney in an additive manner. The combined risk for each patient comprises both acute exposure and insult causing AKI and chronic conditions and patient related factors that define how susceptible each patient is to develop AKI.

\section{Outcome of AKI}

Mode of treatment of AKI in our patients was studied. In our study among 279 AKI cases, 246 (88.1\%) patients were treated conservatively and 33(11.9\%) patients treated with RRT. Hence most patients were treated conservatively. Previous study by Bagshawsm et al, where $67.4 \%$ patients were treated conservatively, and $32.6 \%$ patient were treated by RRT.[29] In our study among 279 cases; 15 (45.5\%) cases with AKI who received RRT survived and 18 (54.5\%) expired, whereas out of 279, 246 cases who received conservative management survived. The acute renal failure trial network study found that increasing the intensity of dialysis did not improve clinical outcome.[30]

In another study 22 patients were treated with haemodialysis survived; out of 46 patient who were treated conservatively $17.4 \%$ expired.[30] Previous Indian studies by Prakash et al [31] and Singh et al,[32] reported that 34\% and $20.58 \%$ of the cases respectively required RRT. Renal replacement therapy requirement in recent Indian based study on KDIGO is $29.43 \% .{ }^{[33]}$ Delay in initiating dialysis has been shown to contribute to poor outcome with studies even suggesting improved outcome with early initiation of dialysis treatment (34). The lack of uniform guidelines on when to initiate RRT makes it a complex end point in studies and complicates the assessment of how RRT affects patient outcome.[33]

\section{CONCLUSIONS}

In our study the incidence of AKI is high at $56.1 \%$. There is significant association between sepsis patients with AKI and comorbidity, high RIFLE score and mortality, RRT and mortality. We have to consider factors like aetiology, increasing patient age, existence of comorbid condition like diabetes, heart disease, pre-existing renal disease, vascular disease, septic shock, respiratory failure which will increase the rate of mortality. So, further prospective study using KDIGO criteria in small increase in creatinine is needed to identify more precise data regarding incidence and clinical outcome. Specific goals for reducing incidence and mortality of acute kidney injury has to be formulated and uniform guidelines regarding initiating RRT should be formed in order to achieve 0 by 2025 initiative.

\section{REFERENCES}

[1] Li PK, Burdmann EA, Mehta RL, et al. Acute kidney injury: global health alert. Kidney International 2013;83(3):372-6.

[2] Case J, Khan S, Khalid R, et al. Epidemiology of acute kidney injury in the intensive care unit. Crit Care Res Pract 2013;2013:479730.

[3] Cruz DN, Ronco C. Acute kidney injury in the intensive care unit: current trends in-incidence and outcome. Crit Care 2007;11(4):149.

[4] Uchino S, Kellum JA, Bellomo R, et al. BEST for kidney investigators. Acute Renal failure in critically ill patients: a multinational, multicentre study. JAMA 2005;294(7):813-8.

[5] Waikar SS, Bonventre JV. Acute kidney injury. In: Longo DL, Fauci AS, Kasper DL, et al. eds. Harrison's Principles of internal medicine. 19 $9^{\text {th }}$ edn. New York: McGraw-Hill Publication 2015: p. 1799-805.

[6] Bellomo R, Ronco C, Kellum JA, et al. Acute renal failure definition, outcome measures, animal models, fluid therapy and information technology needs: The Second International Consensus Conference of the Acute Dialysis Quality Initiative (ADQI) Group. Critical Care 2004;8(4):R204-12.

[7] Fujii T, Uchino S, Takinami $\mathrm{M}$, et al. Validation of the kidney disease improving global outcomes criteria for aki and comparison of three criteria for AKI and comparison of three criteria in hospitalised patients. Clin J Am Soc Nephrol 2014;9(5):848-54.

[8] Susantitaphong P, Cruz DN, Cerda J, et al. World incidence of AKI: a meta-analysis. Clin J Am Soc Nephrol 2013;8(9):1482-93.

[9] Mehta RL, Kellum JA, Shah SV. Acute Kidney Injury Network: report of an initiative to improve outcome in acute kidney injury. Critical Care 2007;11(2)-R31.

[10] Bouchard J, Mehta RL. Acute kidney injury in western countries. Kidney Dis (Basel, Switzerland) 2016;2(3):103-10.

[11] Langenburg C, Wan L, Egi M, et al. Renal blood flow and function during recovery from experimental septic acute injury. Intensive Care Medicine 2007;33(9):1614-8.

[12] Gomez H, Ince C, De Backer D, et al. A unified theory of sepsis induced acute kidney injury: inflammation, microcirculatory dysfunction, bioenergetics and the 
tubular cell adaptation to injury. Shock (Augusta, Ga) 2014;41(1):3-11.

[13] Jha V, Kumar V. Acute kidney injury: validating the KDIGO definition and staging-one step at a time. Nature Reviews Nephrology 2014;10(10):550-1.

[14] Farooqi S, Dickhout JG. Major comorbid disease process associated with increased incidence of acute kidney injury. World Journal of Nephrology 2016;5(2):139-46.

[15] Lamerie NH, Bagga A, Cruz D, et al. Acute kidney injury: an increasing global concern. The Lancet 2013;382(9887):170-9.

[16] Yokota LG, Sampaio BM, Rocha EP, et al. Acute kidney injury in elderly patients: narrative review on incidence, risk factors and mortality. International Journal of Nephrology Renovasc Dis 2018;11:217-24.

[17] Pereira MB, Zanetta DMT, Abdulkader RCRM. The real importance of pre-exsisting comorbidities on long-term mortality after acute kidney injury. PLoS One 2012;7(10):e47746.

[18] Hoste EA, Clermont G, Kersten A, et al. RIFLE criteria for acute kidney injury are associated with hospital mortality in critically ill patients: a cohort analysis. Critical Care 2006;10(3):R73.

[19] Prakash J, Singh TB, Ghosh B, et al. Changing epidemiology of community - acquired acute kidney injury in developing countries: analysis of 2405 cases in 26 years from eastern India. Clin Kidney J 2013;6:150-5.

[20] Chertow GM, Burdick E, Honour M, et al. Acute kidney injury, mortality, length of stay and costs in hospitalized patients. J Am Soc Nephrol 2005;16(11):3365-70.

[21] Kerr M, Bedford M, Matthews B, et al. The economic impact of acute kidney injury in England. Nephrol Dial Transplant 2014;29(7):1362-8.

[22] Sterwart J, Findlay G, Smith N, et al. Acute kidney injury: adding insult to injury. Natl Confid Enq into Patient Outcome \& Death 2009.

[23] Mehta RL, Cerdá J, Burdmann EA, et al. International Society of Nephrology's 0by25 initiative for acute kidney injury (zero preventable deaths by 2025): a human rights case for nephrology. Lancet 2015;385(9987):2616-43.
[24] Wijewickrama ES, Ratnayake GM, Wikramaratne C, et al. Incidences and clinical outcomes of acute kidney injury in ICU: a prospective observational study in Sri Lanka. BMC Research Notes 2014;7:305.

[25] Ali T, Khan I, Simpson W, et al. Incidence and outcome in acute kidney injury: a comprehensive population-based study. Journal of American Society Nephrology 2007;18(4):1292-8.

[26] Teo SH, Lee KG, Koniman R, et al. A prospective study of clinical characteristics and outcomes of acute kidney injury in a tertiary care centre. BMC Nephrology 2019;20:282.

[27] Mehta RL, Pascual MT, Soroko S, et al. Spectrum of acute renal failure in the intensive care unit: the PICARD experience. Kidney International 2004;66(4):1613-21.

[28] Hsu CY, Chertow GM, McCulloch CE, et al. Nonrecovery of kidney function and death after acute on chronic renal failure. Clinical journal of the American Society of Nephrlogy 2009;4(5):891-8.

[29] Bagshaw SM, Laupland KB, Doig CJ, et al. Prognosis for long term survival and renal recovery in critically ill patients with severe acute renal failure: a population based study. Critical Car 2005;9(6):R700-9.

[30] Palevsky PM, Zhang JH, O'Connor TZ, et al. Intensity of renal support in critically ill patients with acute renal failure. New England Journal of Medicine 2008;359(1):720.

[31] Prakash J, Singh SP, Kumar OM et al. Hospital acquired acute renal failure. Indian J Nephrology 1996;6:9-13.

[32] Singh TB, Rathore SS, Choudary TA, et al. Hospital acquired acute kidney injury in medical, surgical, and intensive care unit: a comparative study. Indian Journal of Nephrology 2013;23(1):24-9.

[33] Bhadade R, De'Souza R, Harde MJ, et al. A prospective study of acute kidney injury according to KDIGO definition and its mortality predictors. Journal of the Association of Physicians of India 2016;64(12):22-8.

[34] Pannu N, Klarenbach S, Wiebe N, et al. Renal replacement therapy in patients with acute renal failure: a systematic review. JAMA 2008;299(7):793-805. 